\title{
A DC Scheme to Maximize the Benefits of the Public Sector Employees Based on Behavioral Finance
}

\author{
Yueling Zhao \\ Xiamen University, Xiamen, Fujian, China
}

\begin{abstract}
This paper introduces DB and DC pension plans, reviews the literature of DC pension plans, and puts forward three application strategies: automatic registration default contribution rate and annual automatic growth contribution rate, the risk tolerance level of different employees was evaluated by questionnaire survey, and individual investment choice of employees with different risk tolerance.
\end{abstract}

Key words: DC pension scheme; risk tolerance; contribution rate; investment

\section{Introduction}

DC plan is a pension plan in which contributions rather than benefits are specified, such as 401(k) plans in the United States, group personal pension schemes in the United Kingdom, and superannuation plans in Australia. Individuals will invest part of their wages while working, expecting to draw on the accumulated funds to provide income during retirement or to transfer some of their wealth to their heirs. Compared with DB pension plan, DC pension plan has the following advantages: First, it is simple and flexible, so that the employer is not liable to provide a certain amount of pension in the future. Second, pensions are credited to individual accounts, which are highly attractive to employees. Third, the enterprise annuity of this plan does not have to participate in the reinsurance of the termination of the pension plan. However, since many public sectors in China adopt DB pension plan, it is not easy for employees to change the long-accustomed contribution mode. In addition, because the characteristic of DC pension is that the pay after the treatment cannot be decided, the investment risk of account and fund is assumed by policy-holder individual entirely, so how to realize the optimal investment that decides contributive type annuities becomes the problem that financial scholars pay close attention to. In recent years, scholars in China and abroad have done a lot of research in this field.

\section{Literature Review}

\subsection{DC scheme}

In recent years, there has been a major shift in pension provision in US and the UK, from employers offering defined benefit pensions to employees, to a "self-directed" defined contribution basis, where employees take individual risks and the contributions, and investment returns they earn will be sufficient to support a comfortable retirement. Alistair Byrne (2004) described DC plan as a plan in which employees can choose from a series of investment choices. These funds have accumulated investment returns and can provide retirement income directly or by purchasing annuities. The trend of 
defined contribution (DC) provides individual employees with more choices on how to save for retirement. The traditional view of economics is that increasing choice may improve welfare. However, it is controversial that the lack of interest or knowledge will increase the risk of costly mistakes by a large number of investors. Surveys show that many people find it is difficult to understand and deal with the choices they face when saving for retirement. According to Mullainathan and Thaler (2000), there are "bounds" to human rationality, self-control and self-interest. Experimental evidence shows that most people use rules of thumb (or "heuristics") to cope with the limitations of their abilities, but these heuristics can lead to systematic errors in the decision-making process in some cases.

\subsection{Status quo bias}

According to Ackert L. and Deaves R. (2010), status quo bias refers to a phenomenon that prefer staying at the current state rather than changing. And the preference for the current state also follows from comfort-seeking. People are resistant to change, fearing the regret that might follow if active steps are undertaken to alter the status quo. In investment decisions, this type of bias can explain people's preference to maintain their current portfolio instead of taking decisions based on comparing the returns of current holdings with the returns of available stocks. This is especially true when decisions are complex and many attractive choices exist (Tversky and Shafrin, 1992). Investors typically face many investment decisions and having too much choice might lead them to avoid making changes, because changes mean that some previous purchase decisions were poor (Thalor, 1990). Status quo bias plays a significant role in the pension field. MacFarland et al. noted that although about half of American adults have the attitude characteristics of becoming "planners" and are actively interested in providing for their retirement life, more than one third of them are "Dodgers", who are either frightened by financial problems or not interested at all. Therefore, in the absence of automatic enrollment, these employees tend to maintain the status quo of not joining a pension scheme.

\subsection{Anchoring bias}

Anchoring refers to the tendency to attach or "anchor" the thoughts to a reference point according to Vasile Dedu (2010). Anchor bias can occur anywhere in the financial decision-making process, from key forecast inputs, such as sales volume and commodity prices, to final outputs, such as cash flow and security prices. Historical values, such as acquisition prices, are common anchors. This applies to the value necessary to achieve a goal, such as achieving a target return or generating a specific amount of net income. Some of these anchors like absolute historical value and the value necessary to achieve the goal, may be harmful to the investment goal. For instance, some investors tend to invest heavily in the stocks of companies that have fallen "too much" in a "too short" period of time, regardless of the fundamental matters. Investors anchor on the recent "high" and consider that the price drop provides an opportunity to buy the stock at a discount. These values have nothing to do with market pricing and will lead to irrational financial decisions made by market participants, such as financial analysts or investors. Many analysts encourage investors to reject these types of anchors. Other anchors may help when market participants cope with the complexity and uncertainty inherent in an information overload environment.

\section{$2.41 / \mathrm{n}$ diversification heuristic}

In an experimental setting, Bernartzi and Thaler(2001) look for evidence of " $1 / \mathrm{n}$ diversification heuristics", this heuristics leads participants to allocate their investment equally in the " $\mathrm{n}$ " funds provided, while little consideration is given to the composition of the underlying assets of the fund. And the motivation for variety-seeking is it makes choice simpler, thus saving time and reducing decision conflict. As employers and individuals shift from defined benefit pension plans to defined contribution pension plans, the decision-making around retirement plans and savings becomes more and more complex. The level of personal financial ability is likely to determine the nature and complexity of the heuristic and 
savings model. In the transition to a fixed contribution system, individual decision-making may also be the most vulnerable. From a behavioral perspective, any rule of thumb that helps to reduce the complexity of decisions and choices people face is seen as a benefit. The more rules are based on empirical observations of people's attitudes, environments, and characteristics, including their financial capabilities, the better. However, the existing rules of thumb may have nothing to do with ensuring adequate retirement benefits. DWP's 2010 study found that many people's rules of thumb are based on their current income or wealth, rather than their future needs. This requires people to follow the rules of thumb related to future needs.

\section{Applications}

3.1 Automatic enrollment with default contribution and an annual automatic growth contribution rate

Public sector employees are automatically enrolled in defined-contribution schemes when they are hired and have the option to opt out. Meanwhile, for new employees under 30, the default contribution rate starts at $3 \%$ and automatically increases by $1 \%$ a year thereafter. The employee has the right to adjust the annual contribution rate anytime they want. For new employees between the ages of 30 to 35,36 to 40,41 to 50 , and above 50, the default rate is 5 percent, 7 percent, 10 per cent and 15 percent at the beginning respectively.

Choi et al. noted that $76 \%$ of automatic enrollment plans had default contribution rates of $2 \%$ or $3 \%$, and $65 \%$ to $87 \%$ of new employees in research companies adopted default funds and default contribution rates. In addition, Samuelson and Zeckhauser believe that even if employees refuse to take immediate action, they are willing to make more savings commitments in the future, and once the initial commitment is made, few people make the effort to change it. Therefore, the default contribution rate and the annual automatic growth contribution rate can ensure a certain saving rate for investors unwilling to change the status quo, thus increasing their interests.

3.2 Evaluate the risk tolerance levels of different employees via questionnaires

Before employees begin DC schemes, a questionnaire is issued to each employee to assess their risk tolerance preferences. Risk tolerance is divided into risk aversion and risk preference, and the test results will be told to the audience. The questionnaire will include questions concerning the source of employees' income, household assets and liabilities, investment preference, investment experience, expected benefits and so on. The result of the risk assessment will be regarded as an anchor by the employees, so they will be more inclined to choose according to their own risk tolerance preferences in the future portfolio selection. This will allow them to get a return or a loss that doesn't deviate too much from what they are looking for, so that they will not have a negative attitude toward defined-contribution scheme.

\subsection{Personalized investment choices for employees with different risk tolerance}

According to the result of the questionnaire in terms of the risk tolerance, we provide different recommended funds for employees to make portfolios. For those who are risk aversion, we will give them eight funds with three bond funds, three balanced funds and two stock funds. For those who are risk preference, we will give them eight funds with three stock funds, three balanced funds and two bond funds.

On a risk scale of $0-5,5$ is "very high risk", bonds will be rated between 0 to 2 , while stocks will be rated between 2 to 5. Among bond funds, there are bound to include five different bonds with both high and low risk grades. The same situation goes in the stock funds. The balanced funds include two to three bonds and two to three stocks with different risk levels. Different stocks and bonds had better come from different industries to spread the risk. Also, the number of proposed portfolios provided to employees should be appropriate. If options are too few, members may argue that investment options are limited, but too much options may complicate the options, and therefore not in the best interests of members. 


\section{Conclusions}

Whether investors use simple $1 / \mathrm{n}$ heuristics to allocate between funds or take implicit guidance from the range of funds on offer, the structure of the pension scheme can significantly influence the asset allocation chosen by many plan participants. So the pension scheme should be well-organized to maximize the potential benefits of employees. The main issues involve the arrangements for joining the scheme (opt in or opt out), default contribution rate, default fund selection, and the scope and nature of fund selection. Besides, there are also questions about the nature of the information and advice provided to employees.

In the defined-contribution scheme in this paper, employees will automatically join the plan when they are hired with default contribution and an annual automatic growth contribution rate to increase the participation and contribution rate of the DC scheme. Employees will conduct a questionnaire to determine their risk tolerance level, and different portfolio choices will be provided to them based on this, which can make the income and loss meet employees' expectations, increase their enthusiasm to participate in the DC scheme, and maximize the benefits of employees in the long-term investment.

\section{Conflicts of Interest}

The author declares no conflicts of interest regarding the publication of this paper.

\section{References}

[1] Keys B. J., Pope D. G. and Pope J. C. (2016). Failure to Refinance. Journal of Financial Economics, 122(3): 482499.

[2] Sautua S. I. (2017). Does Uncertainty Cause Inertia in Decision Making? An Experimental Study of the Role of Regret Aversion and Indecisiveness. Journal of Economic Behavior \& Organization, 136(C): 1-14.

[3] Goda G. S., Levy M. R., Manchester C. F., Sojourner A. and Tasoff J. (2020). Who is a Passive Saver under Optin and Auto-enrollment? Journal of Economic Behavior \& Organization, 173(C): 301-321. 